\title{
Kajian Etnomedisin dalam Pengobatan Tradisional pada Ulkus Kaki Diabetik (UKD) di Bali
}

\author{
Dwi Arymbhi Sanjaya ${ }^{1}$, Putu Era Sandhi Kusuma Yuda ${ }^{1}$, Erna Cahyaningsih ${ }^{1}$, Luh Risma Putri \\ Rahayu $^{1}$ dan Made Agus Deny Mahendra Putra ${ }^{1}$ \\ ${ }^{1}$ Fakultas Farmasi Universitas Mahasaraswati Denpasar, Jl. Kamboja No. 11 A, Denpasar, Bali 80236
}

Reception date of the manuscript: 28 November 2020

Acceptance date of the manuscript: 4 Desember 2021

Publication date: 31 Desember 2021

\begin{abstract}
One of the complications that occur due to diabetes mellitus (DM) is Diabetic Foot Ulcer (UKD). UKD is an incidence of injuries that occur on the feet of people with diabetes due to complications of microangiopathy and macroangiopathy which can cause disability and even death. This study aims to identify and document traditional medicine used by traditional healers in Bali to treat UKD. This research was conducted using a comparative qualitative descriptive method that compares the data obtained from in-depth interviews and questionnaires filling with literature. Data collection was carried out by in-depth interviews with BATTRA in Bali as informants who have competence in the field of traditional UKD medicine. Determination of informants in this study using snowball sampling technique. The results of the research were carried out from the data obtained by 8 (eight) sources and obtained 10 ingredients, consisting of 6 (six) ingredients used topically and 4 (four) ingredients used orally. The main ingredient used in topical ingredients is honey. Of the 10 ingredients, there are 15 types of medicinal plants used for the treatment of UKD. Most of the medicinal plants used are aloe vera, garlic, pepper, onion and sandalwood.
\end{abstract}

Keywords—Sandalwood, Honey, Snowball sampling, Medicinal plants, Diabetic foot ulcers.

\begin{abstract}
Abstrak - Salah satu komplikasi yang terjadi akibat diabetes mellitus (DM) adalah Ulkus Kaki Diabetik (UKD). UKD merupakan kejadian luka yang timbul pada kaki penderita DM akibat komplikasi mikroangiopati dan makroangiopati yang dapat menimbulkan kecacatan bahkan kematian. Penelitian ini bertujuan untuk mengetahui dan mendokumentasikan pengobatan tradisional yang digunakan oleh pengobat tradisional di Bali untuk mengobati UKD. Penelitian ini dilaksanakan dengan menggunakan metode deskriptif kualitatif komparatif yang membandingkan data yang diperoleh dari hasil wawancara mendalam dan pengisian angket dengan pustaka. Pengumpulan data dilakukan dengan wawancara mendalam pada pengobat tradisional (BATTRA) di Bali sebagai informan yang memiliki kompetensi di bidang pengobatan tradisional UKD. Teknik sampling yang digunakan dalam penelitian ini yaitu teknik snowball sampling. Dari hasil penelitian diperoleh sebanyak 10 ramuan, yang terdiri dari 6 (enam) ramuan yang digunakan secara topikal dan 4 (empat) ramuan yang digunakan secara oral. Bahan utama yang digunakan dalam ramuan topikal adalah madu. Dari 10 ramuan terdapat 15 jenis tanaman obat yang digunakan untuk pengobatan UKD. Tanaman obat terbanyak yang digunakan adalah lidah buaya, bawang putih, merica, bawang merah dan cendana.
\end{abstract}

Kata Kunci-Cendana, Madu, Snowball sampling, Tanaman obat, Ulkus kaki diabetik.

\section{Pendahuluan}

Ulkus Kaki Diabetik (UKD) merupakan kejadian luka yang timbul pada kaki penderita diabetes mellitus (DM) akibat komplikasi mikroangiopati, yaitu terjadinya neuropati perifer. Neuropati perifer menyebabkan hilangnya sensasi di daerah distal kaki dan komplikasi akan diikuti yang diawali oleh terjadinya penyumbatan pembuluh darah (trombosis). Terjadinya trombosis akan mengganggu suplai darah ke daerah luka sehingga akan menghambat proses penyembuhan luka dan menyebabkan terjadinya ulkus (Agistia et al., 2017;

Penulis koresponden: Putu Era Sandhi Kusuma Yuda, erasandhi@unmas.ac.id
Everett \& Mathioudakis, 2018)

Kompleksitas permasalahan kaki diabetes, mulai dari risiko terjadi amputasi sampai kematian karena UKD memerlukan penatalaksanaan yang tepat. Hingga saat ini, angka kejadian amputasi dan kematian masih cukup tinggi. Selain menurunkan kualitas hidup, UKD juga menghabiskan biaya yang cukup besar untuk pengobatan. Pada tahun 2017, beban ekonomi yang harus ditanggung oleh pasien untuk setiap pengobatan UKD di India sebesar US\$1960, sedangkan pada tahun 2019 di Indonesia memerlukan biaya sebesar Rp.889.487.600 untuk biaya tindakan per pasien (Decroli (2011); Ghosh \& Valia (2017)). Dapat disimpulkan bahwa UKD tidak hanya dapat menurunkan kualitas hidup, tetapi juga menghabiskan biaya yang besar untuk pengobatan, sehingga perlu dilakukan pencarian alternatif pengobatan ba- 
TABEL 1: DistribUSi FREKUENSI KARAKTERISTIK RESPONDEN)

\begin{tabular}{llcc}
\hline Karakteristik & & Frekuensi (f) & Persen (\%) \\
\hline \multirow{2}{*}{ Jenis Kelamin } & Laki - laki & 5 & $62,5 \%$ \\
& Perempuan & 3 & $37,5 \%$ \\
& 23 tahun & 1 & $12,5 \%$ \\
& 27 tahun & 1 & $12,5 \%$ \\
Umur & 30 tahun & 1 & $12,5 \%$ \\
& 34 tahun & 2 & $25 \%$ \\
& 39 tahun & 1 & $12,5 \%$ \\
Kabupaten & 40 tahun & 1 & $12,5 \%$ \\
& 54 tahun & 1 & $12,5 \%$ \\
Kategori Pekerjaan & Denpasar & 4 & $50 \%$ \\
& Badung & 3 & $37,5 \%$ \\
Tingkat Pendidikan & Tenaga Kesehatan & 7 & $12,5 \%$ \\
& Umum & 1 & $87,5 \%$ \\
& Pasca Sarjana (S-2) & 3 & $12,5 \%$ \\
& Sarjana & 4 & $37,5 \%$ \\
& Diploma & 1 & $50 \%$ \\
& & & \\
& & $12,5 \%$ \\
\hline \multirow{5}{*}{ Klungung } & &
\end{tabular}

ru dengan harapan biaya yang lebih kecil dibandingkan dengan biaya pengobatan sebelumnya.

Pengobatan alternatif yang dapat digunakan salah satunya adalah penggunaan obat tradisional dari bahan alam. Review untuk mencari obat berbasis bahan alam dalam penanganan UKD belum pernah dilakukan hingga saat ini. Oleh karena itu, perlu dilakukan kajian etnomedisin pada kelompok pengobat tradisional yang memiliki pengalaman dalam merawat dan mengobati pasien UKD untuk mengeksplorasi lebih dalam terkait penggunaan tanaman obat tradisional untuk mengobati UKD dalam upaya mengumpulkan kandidatkandidat tanaman unggul yang dapat digunakan sebagai informasi penting dalam pengobatan UKD. Penelitian ini akan menggunakan desain penelitian deskriptif komparatif untuk membandingkan data primer yang diperoleh dari pengobat tradisional Bali yang mengobati UKD dan data sekunder yang diperoleh dari jurnal yang terpublikasi.

\section{BAHAN DAN METOdE}

\section{Bahan dan Alat}

Alat yang digunakan dalam penelitian ini adalah alat perekam suara dan instrumen yang digunakan adalah angket (pertanyaan terbuka) yang menggunakan Bahasa Indonesia sebagai pedoman wawancara dan catatan lapangan/field note.

\section{Metode}

Penelitian ini merupakan penelitian deskriptif kualitatif komparatif yang akan membandingkan data primer yang berasal dari narasumber dan data sekunder dari jurnal-jurnal ilmiah yang terpublikasi dengan variable tunggal yang diamati dalam penelitian ini yaitu jenis-jenis tanaman obat tradisional yang digunakan untuk mengobati Ulkus Kaki Diabetik (UKD). Penelitian ini dilakukan dalam periode OktoberDesember 2019.

Populasi dalam penelitian ini adalah pengobat tradisional (BATTRA) yang menetap di Bali. Sampel dalam penelitian ini adalah BATTRA yang menetap di Bali yang melakukan pengobatan Ulkus Kaki Diabetik (UKD). Teknik pengambilan sampel dilakukan dengan teknik snowball sampling dengan kriteria inklusi bagi narasumber dalam penelitian ini ada- lah BATTRA yang melakukan pengobatan tradisional untuk mengobati UKD dan berdomisili di Bali. Kriteria eksklusi dalam penelitian ini yaitu BATTRA yang tidak memberikan informasi yang lengkap sesuai panduan wawancara.

Tahap pengumpulan data diawali dengan kedatangan peneliti ke BATTRA yang terlebih dahulu telah diketahui mengobati pasien UKD. Selanjutnya, dari narasumber pertama akan diperoleh informasi BATTRA lain yang mengobati UKD dengan menggunakan tanaman obat dan seterusnya. Data yang diperoleh dari penelitian ini terlebih dahulu direduksi atau dipilih sesuai dengan tujuan penelitian. Setelah itu, dilakukan teknik analisis yang mencakup tiga kegiatan yang bersamaan, yaitu : 1) reduksi data, 2) penyajian data, dan 3) penarikan kesimpulan (verifikasi).

\section{HASIL}

Hasil pemetaan informan yang melakukan pengobatan tradisional UKD yang berhasil diwawancarai yaitu 8 (delapan) orang sebagai informan yang merupakan pengobat tradisional yang sering melakukan pengobatan tradisional kepada pasien UKD. Secara umum para narasumber merupakan tenaga kesehatan yang telah menempuh pendidikan di perguruan tinggi. Demografi para narasumber dapat dilihat pada tabel 1 .

Dari data yang diperoleh dari 8 (delapan) narasumber diperoleh sebanyak 10 ramuan, yang terdiri dari 6 ramuan yang digunakan secara topikal dan 4 ramuan yang digunakan secara oral yang dapat dilihat pada Tabel 2. Bahan utama yang digunakan dalam ramuan topikal adalah madu.

Dari 10 ramuan terdapat 15 jenis tanaman obat yang digunakan untuk pengobatan UKD yang terlihat pada Gambar 1. Tanaman yang sering digunakan untuk mengobati UKD yaitu tanaman lidah buaya (Aloe vera), bawang putih (Allium sativum), bawang merah (Allium cepa), cendana (Santalum album), dan merica (Piper nigrum).

\section{Pembahasan}

Dalam penelitian ini, narasumber berasal dari berbagai kabupaten/kota Badung, Denpasar dan Klungkung. Narasumber yang diwawancarai sebagian besar berperan sebagai Tenaga Kesehatan yang sudah berpengalaman dalam pengoba- 
TABel 2: PemanfaAtan Tanaman Obat UKD)

\begin{tabular}{|c|c|c|c|c|c|}
\hline No. & Jenis Ramuan & $\begin{array}{l}\text { Cara } \\
\text { Penyiapan }\end{array}$ & $\begin{array}{l}\text { Cara } \\
\text { Pemakaian }\end{array}$ & Frekuensi & $\begin{array}{l}\text { Lama } \\
\text { Pengobatan }\end{array}$ \\
\hline 1. & $\begin{array}{l}\text { Daun jambu biji } \\
\text { (Psidium guajava) }\end{array}$ & Direbus & $\begin{array}{l}\text { Direbus ambil } \\
\text { airnya untuk } \\
\text { mencuci luka }\end{array}$ & $2 \times$ sehari & $1-4$ bulan \\
\hline 2. & $\begin{array}{l}\text { Lidah Buaya (Aloevera ) } \\
\text { dan madu }\end{array}$ & Dioleskan & Dioleskan pada luka & $2 \times$ sehari dioleskan & $10 \mathrm{~s} / \mathrm{d} 14$ hari \\
\hline 3. & $\begin{array}{l}\text { Bawang putih (Allium sativum) } \\
\text { dan madu }\end{array}$ & $\begin{array}{l}\text { Dibuat dalam } \\
\text { bentuk salep } \\
\text { (garlic salep) }\end{array}$ & Dioleskan & $1 \times$ sehari & $1-3$ bulan \\
\hline 4. & $\begin{array}{l}\text { Daun pegagan (Centella asiatica) } \\
\text { dan madu }\end{array}$ & Dihaluskan & $\begin{array}{l}\text { Ditempelkan } \\
\text { pada luka }\end{array}$ & $2 \times$ sehari & $1-3$ bulan \\
\hline 5. & Minyak zaitun dan madu & Dioleskan & Dioleskan & $2 \times$ sehari & $1-5$ bulan \\
\hline 6. & Pare (Momordica charantia L.) & Direbus & $\begin{array}{l}\text { Minum air rebusan } \\
\text { pare }\end{array}$ & $2 \times$ sehari & 3 minggu \\
\hline 7. & $\begin{array}{l}\text { Jahe (Zingiber officinale), } \\
\text { Cabe Jawa (Piper retrofractum), } \\
\text { Merica (Piper nigrum), } \\
\text { dan Air Kelapa (Cocos nucifera) }\end{array}$ & $\begin{array}{l}\text { 1. Dibersihkan } \\
\text { semua bahan } \\
\text { 2. Siapkan kelapa } \\
\text { hijau } 1 \text { buah } \\
\text { 3. Masukkan semua } \\
\text { bahan dalam kelapa } \\
\text { hijau tersebut } \\
\text { 4. Panaskan sekitar } \\
\text { 30 menit di atas api sedang } \\
\text { dengan kondisi kelapa } \\
\text { tertutup kembali }\end{array}$ & Diminum air rebusan & $\begin{array}{l}\text { Diminum } 2 \mathrm{x} \text { sehari } \\
\text { setelah makan }\end{array}$ & $1-3$ bulan \\
\hline 8 & $\begin{array}{l}\text { Bawang Merah (Allium cepa), } \\
\text { Kunyit (Curcuma longa), } \\
\text { Cendana (Santalum album), } \\
\text { Akar Manis Glycyrrhiza glabra), } \\
\text { Madu }\end{array}$ & $\begin{array}{l}\text { 1.Dicuci semua } \\
\text { bahan } \\
\text { 2. Haluskan dan } \\
\text { campur semua } \\
\text { bahan }\end{array}$ & $\begin{array}{l}\text { Dioleskan pada } \\
\text { bagian kaki } \\
\text { yang luka }\end{array}$ & Dioleskan 3x sehari & $1-3$ bulan \\
\hline 9 & $\begin{array}{l}\text { Jahe (Zingiber officinale), } \\
\text { Brotowali (Tinospora cordifolia), } \\
\text { Merica (Piper nigrum), } \\
\text { Jangu/ jaringau (Acorus calamus), } \\
\text { san air. }\end{array}$ & $\begin{array}{l}\text { 1. Dibersihkan semua } \\
\text { bahan } \\
\text { 2. Siapkan air } 3 \text { gelas } \\
\text { 3. Masukkan semua bahan } \\
\text { dalam air mendidih } \\
\text { 4. Biarkan hingga } \\
\text { 20-30 menit diatas api } \\
\text { sedang dengan tertutup. }\end{array}$ & $\begin{array}{l}\text { Diminum hasil } \\
\text { rebusan }\end{array}$ & Diminum 3x sehari & $1-3$ bulan \\
\hline 10 & $\begin{array}{l}\text { Bawang Merah (Allium cepa), } \\
\text { Bawang Putih (Garlic), } \\
\text { Cendana (Santalum album), } \\
\text { Lidah Buaya (Aloe vera)Madu }\end{array}$ & $\begin{array}{l}\text { 1. Cuci dan bersihkan } \\
\text { semua bahan } \\
\text { 2. Haluskan dan campur } \\
\text { semua bahan }\end{array}$ & $\begin{array}{l}\text { Dioleskan dibagian } \\
\text { yang akan diobati }\end{array}$ & Dioleskan 3x sehari & $1-3$ bulan \\
\hline
\end{tabular}

tan penyakit UKD. Menurut hasil dari narasumber cara pemanfaatan tanaman tradisional bisa dengan cara direbus, ditumbuk/ dihaluskan, dan bisa juga dengan cara ditempelkan langsung pada luka. Penggunaan obat tradisional ini digunakan sebagai alternatif pengobatan, selain menggunakan obat kimiawi. Dalam melakukan pengobatan tradisional ini dilakukan untuk mencegah terjadinya amputasi pada pasien yang mengalami luka ganggren.

Studi tentang etnomedisin pada dasarnya untuk memahami budaya kesehatan dari sudut pandang masyarakat, terutama sistem medis yang telah menjadi tradisi masyarakat secara turun temurun atau yang dikenal dengan pengobatan tradi- sional. Sistem pengobatan tradisional hingga saat ini masih dapat ditemui di Bali, meskipun praktik-praktik pengobatan modern berkembang pesat dengan munculnya pusat-pusat layanan kesehatan pemerintah maupun swasta. Pengobatan tradisional di Bali maupun di Indonesia dapat dikelompokkan menjadi dua macam yakni cara penyembuhan tradisional atau traditional healing yang terdiri dari pijatan, kompres, akupuntur dan sebagainya serta obat tradisional atau disebut traditional drugs yang menggunakan bahan-bahan yang telah tersedia dari alam sebagai obat untuk menyembuhkan penyakit. Obat tradisional ini terdiri dari tiga jenis yaitu pertama dari sumber nabati yang diambil dari bagian-bagian tum- 


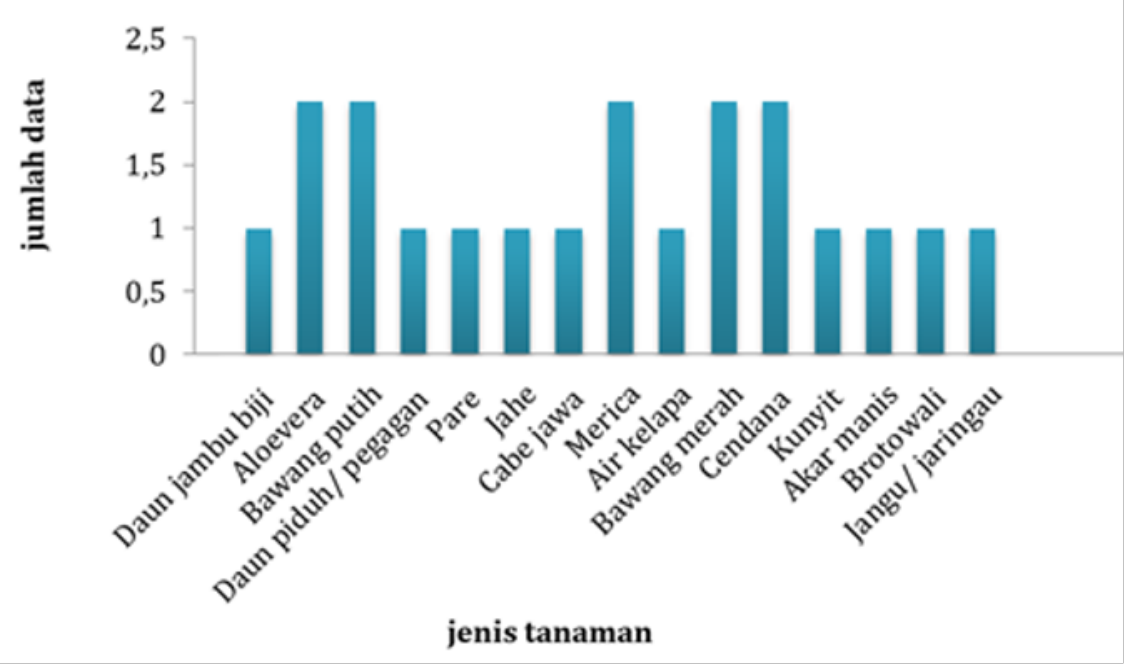

Gambar. 1: Grafik Penggunaan Tanaman Obat untuk UKD

buhan seperti buah, daun, kulit, batang dan sebagainya. Kedua, obat yang diambil dari sumber hewani seperti bagian kelenjar-kelenjar, tulang-tulang maupun dagingnya dan yang ketiga adalah dari sumber mineral atau garam yang bisa didapatkan dari mata air yang keluar dari tanah (Astuti et al. (2017); Rona \& Pramono (2015)).

Tanaman yang digunakan dalam pengobatan UKD yaitu tanaman daun jambu biji (Psidium guajava), lidah buaya (Aloe vera), bawang putih (Allium sativum), daun piduh/pegagan (Centella asiatica), pare (Momordica harantia L.), jahe (Zingiber officinale), cabe jawa (Piper retrofractum), merica (Piper nigrum), air kelapa (Cocos nucifera), bawang merah (Allium cepa), cendana (Santalum album), kunyit (Curcuma longa), akar manis (Glycyrrhiza glabra), brotowali (Tinospora cordifolia), jangu/jaringau (Acorus calamus). Dari tanaman tersebut cara penggunaannya bisa dilakukan dengan direbus lalu diminum dan ditumbuk/dihaluskan dan dicampur dengan madu lalu dioleskan.

Dalam penelitian ayurveda digunakan beberapa jenis tanaman yang sama digunakan dalam pengobatan UKD oleh BATTRA dalam penelitian ini, seperti Jahe (Zingiber officinale), Merica (Piper nigrum), Cendana (Santalum album), Jangu/Jaringau (Acorus calamus), Kunyit (Curcuma longa), dan Brotowali (Tinospora cordifolia). Tanaman-tanaman tersebut memiliki kandungan metabolit sekunder yang berfungsi sebagai antiinflamasi, antibakteri, dan antioksidan yang mampu mempercepat penyembuhan luka. Namun, cara pengolahan bahan-bahan tersebut memiliki perbedaan (Kumar Chandan \& Sharmila KJ (2019); Linn et al. (2017); S. \& H.N. (2017)).

Terkait dengan proses pengumpulan data adapun kendala yang dihadapi oleh penulis yaitu masyarakat tidak bersedia dalam memberikan informasi terkait formula pengobatan tradisional penyakit UKD. Kendala lain yang dihadapi dalam proses pengumpulan data yaitu tidak semua pasien UKD yang mengetahui tentang adanya pengobatan tradisional tetapi, hanya beberapa saja yang menggunakan tanaman obat tradisional, hal tersebut diakibatkan karena untuk pengobatan tradisional penyakit UKD masih ada yang belum per- nah melakukan metode penelitian. Dalam menggunakan ramuan obat tradisional biasanya hanya orang tertentu seperti tidak kunjung sembuh dengan menggunakan obat-obatan kimia dan terlalu lama menggunakan obat kimia serta khawatir dengan adanya efek samping yang ditimbulkan, maka akan beralih menggunakan ramuan obat tradisonal.

\section{KESIMPULAN}

Dari hasil penelitian dapat disimpulkan bahwa terdapat kandidat tanaman obat yang mampu mengobati UKD sehingga berpotensi untuk dikembangkan. Perlu diketahui secara mendalam tata cara Pelaku Etnomedisin dalam hal ini adalah BATTRA dalam memformulasikan bahan ramuan yang diyakini menjadi obat ampuh menyembuhkan UKD sesuai standar Cara Produksi Obat Tradisional yang Baik (CPOTB).

\section{UCAPAN TERIMA KASIH}

Terimakasih penulis ucapkan kepada seluruh informan yang bersedia memberikan informasi yang dibutuhkan oleh peneliti.

\section{Daftar Pustaka}

Agistia, N., Mukhtar, H., \& Nasif, H. (2017). Efektifitas Antibiotik pada Pasien Ulkus Kaki Diabetik. J. Sains Farm. Klin., 4(1), 43.

Astuti, H., Rangga, A., Subowo, A., Hendra, J., Balitbangda, P., Lampung, P., Komisi, A., Pangan, K., Dewan, I., Daerah, R., Perencana, F., Lampung, B. P., Balai, P., Teknologi, P., \& Lampung, P. (2017). Balitbangda Provinsi Lampung IDENTIFICATION OF ETHNOMEDICINE BEHAVIOR AND INFORMATION ON TYPE OF DRUG PLANTS USED AND GROW IN LAMPUNG PROVINCE (STUDY ON HERBAL PARK DEVELOPMENT IN LAMPUNG PROVINCE IN 2017). Journalbalitbangdalampung.Org, 05(03).

Decroli, E. (2011). Diagnostic of Diabetic Foot Ulcer. Bagian Ilmu Penyakit Dalam Fak. Kedokt. Unand/ RSUP Dr. M. Djamil Padang, (pp. 1-16). 
Everett, E., \& Mathioudakis, N. (2018). Update on management of diabetic foot ulcers. Ann. N. Y. Acad. Sci., 1411(1), 153-165.

Ghosh, P., \& Valia, R. (2017). Burden of Diabetic Foot Ulcers in India: Evidence Landscape from Published Literature. Value Heal., 20(9), A485.

Kumar Chandan, \& Sharmila KJ (2019). Medicine COMPARATIVE STUDY OF WOUND HEALING ACTIVITY OF INDIAN MEDICINAL PLANT AND HERB AGAINST DIABETIC FOOT ULCER (PIPER NIGRUM AND ARACHIS HYPOGAEA). Asian J. Pharm. Clin. Res., 12(11), 35-39.

Linn, C., Lam, C., \& Hook, F. (2017). Comparative antipyretic and analgesic activities of. 2019 AYU (An Int. Q. J. Res. Ayurveda), 38(3), 62-66.

Rona, A., \& Pramono, P. (2015). Leksikon Etnomedisin Dalam Pengobatan Tradisional Minangkabau. J. Arbitrer, 2(1), 44.

S., V., \& H.N., S. D. (2017). Ayurvedic management of Ischemic Gangrene due to Diabetes Mellitus - A Case Report. J. Ayurveda Integr. Med. Sci., 2(3). 